\title{
The Establishment of Peculiarities of Spatial and Electronic Structure of Systems N-Alkyl-Substituted-Acetamides- Inorganic Acids
}

\author{
Assyl Boshkayeva ${ }^{1}$, Roza Omarova ${ }^{1}$, Assel Kozhamzharova ${ }^{1}$, Aigul Uvaganova ${ }^{2}$, \\ Gulzira Aitzhanova ${ }^{2}$, Bolat Zhanturiyev ${ }^{1}$, Manas Omurzakov ${ }^{1}$, Daniyar Abdambaev ${ }^{1}$ \\ ${ }^{1}$ Pharmaceutical Faculty, Asfendiyarov Kazakh National Medical University, Almaty, Republic of Kazakhstan \\ ${ }^{2}$ The Faculty "General Medicine", Asfendiyarov Kazakh National Medical University, Almaty, Republic of Kazakhstan

\section{Email address:} \\ kenes65@mail.ru (A. Boshkayeva),omarova-r@list.ru (R. Omarova), assel_kozhamzharova@mail.ru (A. Kozhamzharova), \\ aigul.uvazhanova@gmail.com (A. Uvaganova), sana503@mail.ru (G. Aitzhanova), bolatzhan@kaznmu.kz (B. Zhanturiyev), \\ manas.88@mail.ru (M. Omurzakov),manas.88@mail.ru (D.Abdambaev)
}

\section{To cite this article:}

Assyl Boshkayeva, Roza Omarova, Assel Kozhamzharova, Aigul Uvaganova, Gulzira Aitzhanova, Bolat Zhanturiyev, Manas Omurzakov, Daniyar Abdambaev. The Establishment of Peculiarities of Spatial and Electronic Structure of Systems N-Alkyl-Substituted-AcetamidesInorganic Acids. Clinical Medicine Research. Vol. 5, No. 3, 2016, pp. 45-51. doi: 10.11648/j.cmr.20160503.16

Received: February 20, 2016; Accepted: March 10, 2016; Published: May 20, 2016

\begin{abstract}
Quantum-chemical study of molecular objects, such as organic amine systems protonated inorganic acids, it becomes important not only to establish the characteristics of the geometric and electronic structure of the starting amides and their complexes, but also allows you to set a semi-empirical model of the protonation process by identifying patterns of change in the basic parameters of the structure. Comparative analysis of the characteristics of spatial and electronic structure model systems-substituted-acetamide inorganic acids $\left(\mathrm{HF}, \mathrm{HCl}, \mathrm{H}_{2} \mathrm{SO}_{4}\right)$ on the basis of quantum-chemical calculations by $\mathrm{PM} 3$ bond lengths, the charge characteristics of the ionization potential of the dipole moments and led to the following conclusions: - In systems-alkyl derivatives acetamide hydrofluoric acid is a significant change in the bond lengths and values of the electronic characteristics is not observed; - In systems alkyls acetamide- $\mathrm{HCl}, \mathrm{H}_{2} \mathrm{SO}_{4}$ lengths of $\mathrm{C}=\mathrm{O}$ and $\mathrm{C}-\mathrm{N}$ depend upon the nature of the inorganic acid and the change in the electronic characteristics during protonation independent of acid strength and due to the characteristics of their spatial and electronic structure and nature of the alkyl substituents in amino acetamide group.
\end{abstract}

Keywords: Quantum-Chemical Method, The Geometric Structure, Electronic Structure, Electronic Redistribution, Alkylamides, Inorganic Acids

\section{Introduction}

One of the major problems of modern chemistry is the study of patterns of formation, as well as the properties of the new compounds having the scientific and practical importance. In this respect, especially relevant is a new type of complex compounds - amido acids representing compounds which combine the properties of the starting components with the newly acquired during their formation $[1,2]$. Interest in these compounds is caused by their significance in terms of the application, and the fact that they are relatively poorly understood and therefore are good candidates for theoretical studies of positions of the structure, physical and chemical properties and the relationship between the structure and biological activity. Interest in organic amides and their protonated forms are also associated with the fact that they have a number of useful properties and are widely used. Thus, amides themselves are used in industry as plasticizers paper in the production of artificial leather, PVC, certain radioactive metal extractants are raw materials in the production of polymers, intermediates in the synthesis of dyes and sulfamide drugs, and others.

It is equally important the study of the mechanism of complexation (protonation) systems in the organic amideinorganic acid at the atomic and molecular level, due to its little-studied hitherto.

In literature there are data on the study of heterogeneous 
systems dimethylacetamide with some inorganic acids classical method of dissolution, the synthesis of a series of new amide amic acids this study and the results of some of their physical and chemical properties [1]. As a result of these studies, some conclusions about the impact of the substitution of hydrogen atoms in the amino group of acetamide in the alkyl radicals on the physico-chemical properties dimethylacetamide acids.

Data on the effect of substitution of other alkyl of groups in an amino group of the acetamide in literature are absent. It is obvious that the inclusion of such information may contribute to a clarification in the process of formation of alkyl acetamide acids.

It is known that the main result of complex formation is the change in the geometrical configuration and distribution of the electron density in the molecules of the two participants in this process. That's it in a subsequent and makes all physical, chemical and bioactive properties of the resulting new complexes. Naturally, the most accurate method to determine the parameters of the geometric structure, are the diffraction techniques. However, experience shows [2] that the diffraction methods can not be applied to all connections, which is related primarily to the experimental difficulties of obtaining test specimens in the form of single crystals. In addition, many experimental researches amic acids shown that not all compounds are crystalline. Many of them X-rays. Therefore, to get close to the experimental values of the geometric characteristics of the currently widespread found quantum-chemical calculations of the geometry of the model objects.

Accordingly, the aim of this study was to establish the quantum-chemical laws and change the parameters of the geometric model of the electronic structure of molecules and their alkyl derivatives acetamide compounds with certain inorganic acids, as well as the development of semi-empirical models of complex formation between the components of the process.

The objectives of the study are:

- carrying out quantum-chemical calculation model systems-substituted acetamide - $\mathrm{HF}, \mathrm{HCl}, \mathrm{H}_{2} \mathrm{SO}_{4}$;

- the establishment of spatial structure of the investigated alkylamidoacids.

- assessment of the features of the electronic structure of the investigated alkylamidoacids.

For the calculation was applied semi-empirical quantumchemical method PM3 (Parametric Method 3), which is a modified version of the well-known calculation method MNDO.

It can be obtained by the introduction of a last new expression in design scheme for the skeleton-spanning repulsion and the corresponding redistribution of values of variable and of dependent semi-empirical parameter [3-5].

\section{The Experimental Part}

The objects of study were taken methyl-, dimethyl, ethylacetamide, ftor-, hydrochloric and sulfuric acids.
Comparison of bond lengths values $\mathrm{C}=\mathrm{O}, \mathrm{C}-\mathrm{N}$ in the molecule methylacetamide protonated taken for study inorganic acids, shows that the first of the considered lengths of the links in the transition from the hydrogen fluoride to hydrochloric acid and sulfuric acid is more greatly enhanced, and the second - in the same row, acid decreases. This demonstrates the independence of the data on the strength of the bond lengths of an inorganic acid. However, this is understandable from the standpoint of the electronegativity of hetero atoms, part of a mineral acid and determine its electronic nature.

The lengths of C-C bonds in the backbone of the molecule when it methylacetamide protonation different nature in strength and inorganic acids ( $\mathrm{HF}, \mathrm{HCl}, \mathrm{H}_{2} \mathrm{SO}_{4}$ ) is not changed in magnitude. Interatomic distance $\mathrm{N}-\mathrm{H}$ regardless of the nature of an inorganic acid, involved in protonation, retains its value.

Methylacetamide protonation results in the formation of a new connection, the length of which in the case of hydrofluoric acid and sulfuric acid is comparable, and in the case of hydrochloric - slightly smaller value. From this it follows that this dependence direct bond length is not observed on the strength of the acid. This fact, however, is quite understandable on the basis of the electronic nature of the research undertaken for the acids [6-8]. The presence of the strongest in the case of a mineral acid - hydrochloric - the shortest distance $\mathrm{OH}$ indicates a greater degree of protonation of the amide acid. Significant largest lengths of the new $\mathrm{OH}$ bond in the studied systems show that a new connection is not covalent, and is likely to hydrogen.

Comparison of the lengths of $\mathrm{C}=\mathrm{O}, \mathrm{C}-\mathrm{N}$ in a protonated form methylacetamide with respective bond lengths in protonated forms acetamide shows that the introduction of an amino acetamide instead of a hydrogen atom a methyl group results in a marked increase in the lengths of these links in the protonated forms methylacetamide and this testifies methylacetamide influence of nature on the process of complexation with acids.

The smallest amount of dipole moment characteristic form protonated hydrofluoric acid, and most - to form a protonated sulfuric acid. This phenomenon can be explained by the peculiarities of the spatial and electronic structure of inorganic acids involved in the process of protonation under review alkyl substituted acetamide: the most difficult in this regard is sulfuric acid.

Comparison of the characteristics of the charge depending on the nature of the inorganic acid shows that the greatest change in the characteristic of the oxygen atom for methylacetamide system with sulfuric acid, and the least - a system with hydrofluoric acid. The greatest change in the absolute value of the charge on the nitrogen atom of the typical systems amide with hydrochloric and sulfuric acids. These results indicate charge characteristics independent of strength mineral acid, but it can be explained by the electronic structure of acids, and halogenated acetamidebased systems.

Examination of the characteristics of the charge on 
backbone carbon atoms in the protonated forms methylacetamide shows the following: the absolute value and sign of the charge on the carbon atom bound to the amide group does not change, but the absolute value of the charge on the more distant carbon atom from it increases. At the same time the biggest changes are characteristic of the system of the amide with the most complex in terms of the electronic structure of a molecule of sulfuric acid.

Comparison of bond lengths between the atoms of $\mathrm{C}=\mathrm{O}$ and $\mathrm{C}-\mathrm{N}$ in dimethylacetamide protonated forms depending on the nature of the inorganic acid shows that the strength and the electronic nature of inorganic acids they depend only on systems with dimethylacetamide hydrochloric and sulfuric acids. In case of a system-dimethylacetamide hydrofluoric acid viewed bond lengths remain the same meanings as in the unprotonated form of dimethylacetamide.

Comparison of bond lengths in initial forms and methyl dimethylacetamide together leads to the conclusion that the introduction of a methyl group of the second amino acetamide leads to a significant increase in bond lengths of values of $\mathrm{C}=\mathrm{O}$ and $\mathrm{C}-\mathrm{N}$. The protonated with hydrochloric and sulfuric acids forms dimethylacetamide distances viewed in magnitude greater than in similar forms methylacetamide. In the protonated form of hydrofluoric acid lengths dimethylacetamide noticeable change these bonds compared to the original amide is observed. Observed facts lead to the conclusion that the presence of two methyl groups at the nitrogen atom of the amino group in the molecule results in a change of dimethylacetamide electronic redistribution in the molecule and the related change in the interatomic distances, which increases the process of protonation.

The length of the connection between the nitrogen atom and one carbon atom of methyl groups does not change when protonated molecule of any dimethylacetamide taken acids. The length of the second $\mathrm{C}-\mathrm{N}$-linkages of the molecule at the amide protonation of hydrofluoric acid is reduced to 0,015 $\mathrm{nm}$, whereas in the case of protonation of hydrochloric and sulfuric acids is, as in the previous case, retains its value.

A comparison of the lengths resulting from the protonation of new bonds $\mathrm{O}-\mathrm{H}$ shows that the shortest bond is formed in the case of hydrofluoric acid protonation dimethylacetamide. According to its value, it is covalent. In the case of protonated with hydrochloric and sulfuric acids form this connection, as is the case with similar systems methylacetamide is hydrogen. The lengths of these new linkages $\mathrm{OH}$ quite understandable as in the cases described above, from the standpoint of the nature of inorganic acids.

Comparing the depth of interaction in flowing systems studied, with the power of inorganic acids (pKa) shows that in the case of the process of protonation dimethylacetamide taken inorganic acids for investigating the dependence of the depth of the process of acid strength is observed only for systems with hydrochloric and sulfuric acids.

Comparison dipole moment values shows that the largest antisymmetry characteristic, as in the case methylacetamide, for a system with sulfuric acid. This is confirmed by the magnitude of the charge on the characteristics of atoms in all the systems studied. Their analysis shows the following.

Nitrogen and oxygen atoms are negatively charged amide moiety. However, the redistribution of a negative sign for the charge in the molecule dimethylacetamide is different from the observed redistribution in the molecule methylacetamide. The molecule of dimethylacetamide in the presence of two amino methyl fragments oxygen atom is negative in sign magnitude of charge is higher than a nitrogen atom. Go to the protonated form of the amide has practically no effect on the value of the charge on the oxygen atom. However, the process of protonation dimethylacetamide acids leads to a considerable reduction of the charge on the nitrogen atom in absolute value. The greatest change in the value characteristic of the system of the amide with sulfuric acid. And it is also quite understandable its complex electronic structure.

The largest value for the first ionisation potential characteristic dimethylacetamide system with hydrochloric acid, and the least - for the system with the sulfuric acid. From this it follows that this parameter is directly dependent on the strength of the acid component is observed. Observed almost the same values of the first ionization potentials for forms dimethylacetamide, protonated fluoro and hydrochloric acids, explaining at the moment can not find and require more careful study of the populations of the molecular orbitals of these forms.

Comparison of bond lengths in the protonated forms ethylacetamide shows that protonation of its molecules are all taken to study acids leads to a reduction in the length of the $\mathrm{C}$-C backbone molecule amide in the case of hydrochloric and sulfuric acids, while in a system with hydrofluoric acid value this bond length is maintained.

Protonation ethylacetamide hydrofluoric acid has practically no effect on the lengths of the $\mathrm{C}=\mathrm{O}$ and $\mathrm{C}-\mathrm{N}$. For systems of this amide with hydrochloric and sulfuric acids increase the length of these links. However, depending on the strength of acids involved in protonation, is not observed, but, as in previous cases, is understandable from the standpoint of the electronic structure of these acids.

Comparison of the length of the new $\mathrm{OH}$ bond formed as a result of protonation ethylacetamide inorganic acids shows that the smallest its value is characteristic for a system with hydrofluoric acid, and the largest - for the system with the sulfuric acid, indicating that this bond length is independent of the forces of an inorganic acid taken for the study. It is best observed in the present case law explains the spatial structure of inorganic acids. More spatially compact hydrofluoric acid has a greater opportunity to come to a short distance ethylacetamide molecule, the more cumbersome in this regard sulfuric acid.

Ethylacetamide molecule and its protonated form, as discussed above other alkyl-substituted acetamide and their protonated forms are antisymmetric in terms of the electronic structure, as they are characterized by certain values of the dipole moments. The process of protonation ethylacetamide also increases antisymmetry. The largest increase in the value of the dipole moment of the system characteristic for amide with hydrochloric acid, and the least for a system with 
sulfuric acid. A comparison with the results for the systems based on methyl and dimethylacetamide shows that in these systems is beginning to play a more significant role, not the complexity of the electronic structure of the acid component, and the electronic structure of the alkyl substituent on the nitrogen atom in the molecule of the amide and its spatial arrangement.

As in the case of dimethylacetamide, ethylacetamide greatest in the molecule a negative charge on the carbonyl oxygen is concentrated, while it is on the nitrogen atom is small in absolute value.

Process protonation ethylacetamide acids taken for investigation leads, unlike the cases described above, ambiguous to redistribution of charges on the atoms of nitrogen and oxygen in the amide group. In particular, the charge on the carbonyl oxygen atom in the system of this amide with hydrochloric acid in absolute value decreases, and with hydrofluoric and sulfuric acids systems, on the contrary, increased. The charge on the nitrogen atom of the protonated forms decreases in absolute value less sharply than in the systems discussed above. This phenomenon is also likely to be associated with the electronic structure of the ethyl substituent, and its spatial arrangement.

Values of ionization potentials in the first ethylacetamide$\mathrm{HF}$ system, $\mathrm{HCl}, \mathrm{H}_{2} \mathrm{SO}_{4}$ increases when passing from the sulfuric to the hydrochloric and hydrofluoric acids to hereinafter. Thus, this characteristic is found from the relationship nature inorganic acid).

The results of the geometry optimization are shown below in Figures 1-3.

To evaluate the features the electronic structure of the dipole moments were calculated, the first ionization potential, the charge characteristics of the atoms of the skeleton of the molecules and atoms in the alkyl substituents, as well as the energy frontier MOs (HOMO and LUMO). Results are presented in tables 1-3.

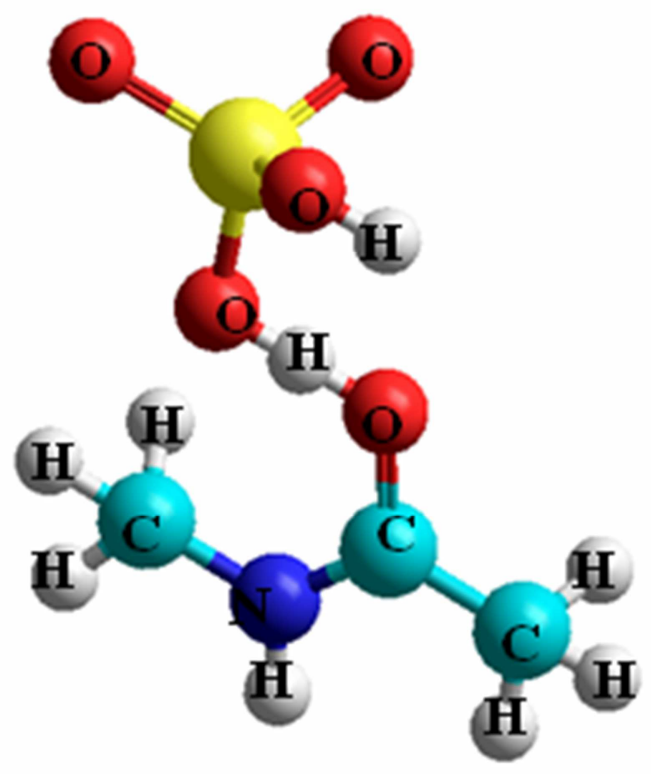

Figure 1. Geometric model molecular systems $\mathrm{CH}_{3} \mathrm{CONH}\left(\mathrm{CH}_{3}\right)-\mathrm{H}_{2} \mathrm{SO}_{4}$.

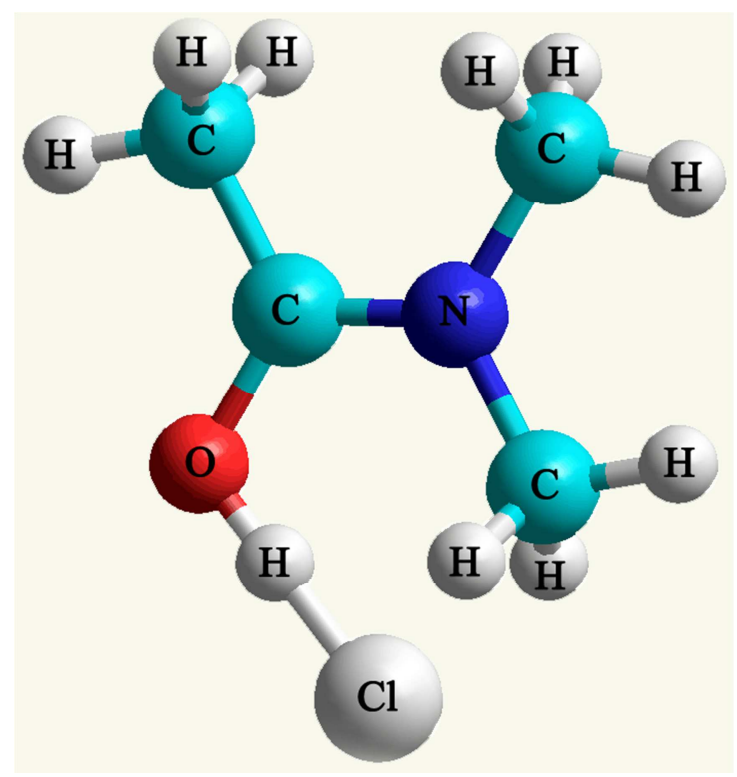

Figure 2. Geometric model molecular systems $\mathrm{CH}_{3} \mathrm{CONH}\left(\mathrm{CH}_{3}\right)_{2}-\mathrm{HCl}$.

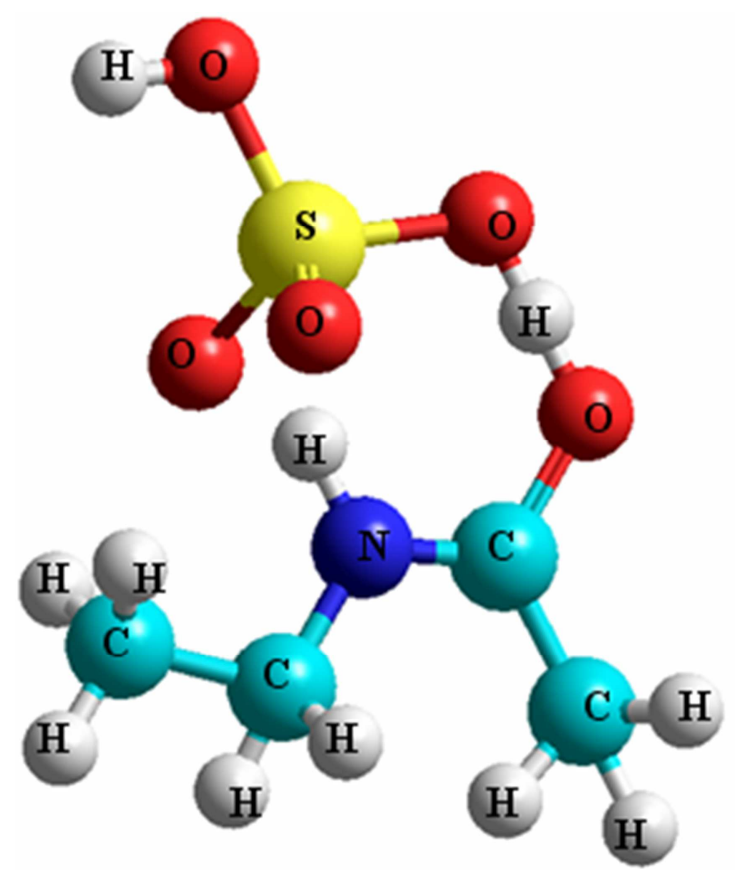

Figure 3. Geometric model molecular systems $\mathrm{CH}_{3} \mathrm{CONH}\left(\mathrm{C}_{2} \mathrm{H}_{5}\right)-\mathrm{H}_{2} \mathrm{SO}_{4}$.

Analysis of the electronic characteristics represented in the tables shows that the process of protonation of $\mathrm{N}$-alkyl derivatives of acetamide results in an increase asymmetry of the electronic structure, evidenced by the value of the charge on the characteristics and the dipole moments of the atoms in the protonated forms of these amides.

Based on the values of the first ionization potential it is seen that the energy consumption for ionization studied objects increases when moving from the initial N-alkylsubstituted acetamide to its protonated forms. Processes protonation of examined acetamide alkyl derivatives have sufficiently high absolute value of the difference between the energies of HOMO and LUMO, indicating mainly the orbital control of the processes. 
Table 1. The dipole moments, ionization potentials (IP), charge characteristics, the HOMO and LUMO energy methylacetamide and its compounds with HF, $\mathrm{HCl}, \mathrm{H}_{2} \mathrm{SO}_{4}$.

\begin{tabular}{|c|c|c|c|c|}
\hline Electronic parameter & $\mathrm{CH}_{3} \mathrm{CONH}\left(\mathrm{CH}_{3}\right)$ & $\mathrm{CH}_{3} \mathrm{CONH}\left(\mathrm{CH}_{3}\right)-\mathrm{HF}$ & $\mathrm{CH}_{3} \mathrm{CONH}\left(\mathrm{CH}_{3}\right)-\mathrm{HCl}$ & $\mathrm{CH}_{3} \mathrm{CONH}\left(\mathrm{CH}_{3}\right)-\mathrm{H}_{2} \mathrm{SO}_{4}$ \\
\hline$\mu, \mathrm{D}$ & 3,06 & 4,75 & 5,39 & 7,26 \\
\hline IP, eV & 9,75 & 10,12 & 10,19 & 10,28 \\
\hline $\mathrm{E}_{\text {номо }}$ & $-9,75$ & $-10,12$ & $-10,19$ & $-10,28$ \\
\hline $\mathrm{E}_{\text {LUMO }}$ & 1,00 & 0,54 & 0,42 & 0,33 \\
\hline$q\left(C_{1}\right)$, a unit of charging & 0,23 & $\mathrm{q}\left(\mathrm{C}_{3}\right) 0,25$ & $\mathrm{q}\left(\mathrm{C}_{3}\right) 0,25$ & $\mathrm{q}\left(\mathrm{C}_{5}\right) 0,26$ \\
\hline$q\left(C_{2}\right)$, a unit of charging & $-0,14$ & $\mathrm{q}\left(\mathrm{C}_{4}\right)-0,14$ & $\mathrm{q}\left(\mathrm{C}_{4}\right)-0,14$ & $q\left(C_{6}\right)-0,14$ \\
\hline$q\left(\mathrm{O}_{6}\right)$, a unit of charging & $-0,37$ & $\mathrm{q}\left(\mathrm{O}_{8}\right)-0,39$ & $\mathrm{q}\left(\mathrm{O}_{8}\right)-0,40$ & $\mathrm{q}\left(\mathrm{O}_{10}\right)-0,42$ \\
\hline $\mathrm{q}\left(\mathrm{N}_{7}\right)$, a unit of charging & $-0,43$ & $\mathrm{q}\left(\mathrm{N}_{9}\right)-0,03$ & $\mathrm{q}\left(\mathrm{N}_{9}\right)-0,2$ & $\mathrm{q}\left(\mathrm{N}_{11}\right)-0,02$ \\
\hline $\mathrm{q}\left(\mathrm{C}_{8}\right)$, a unit of charging & $-0,08$ & $q\left(C_{10}\right)-0,10$ & $q\left(C_{10}\right)-0,10$ & $q\left(C_{12}\right)-0,09$ \\
\hline $\mathrm{q}\left(\mathrm{F}_{1}\right)$, a unit of charging & - & $-0,23$ & - & - \\
\hline $\mathrm{q}\left(\mathrm{Cl}_{1}\right)$, a unit of charging & - & - & $-0,24$ & - \\
\hline $\mathrm{q}\left(\mathrm{S}_{1}\right)$, a unit of charging & - & - & - & 2,50 \\
\hline $\mathrm{q}\left(\mathrm{O}_{2}\right)$, a unit of charging & - & - & - & $-0,83$ \\
\hline $\mathrm{q}\left(\mathrm{O}_{3}\right)$, a unit of charging & - & - & - & $-0,69$ \\
\hline$q\left(\mathrm{O}_{17}\right)$, a unit of charging & - & - & - & $-0,90$ \\
\hline $\mathrm{q}\left(\mathrm{O}_{18}\right)$, a unit of charging & - & - & - & $-0,66$ \\
\hline
\end{tabular}

Table 2. The dipole moments, ionization potentials (IP), charge characteristics, the HOMO and LUMO energy dimethylacetamide and its compounds with HF, $\mathrm{HCl}, \mathrm{H}_{2} \mathrm{SO}_{4}$.

\begin{tabular}{|c|c|c|c|c|}
\hline Electronic parameter & $\mathrm{CH}_{3} \mathrm{CONH}\left(\mathrm{CH}_{3}\right)_{2}$ & $\mathrm{CH}_{3} \mathrm{CONH}\left(\mathrm{CH}_{3}\right)_{2}-\mathrm{HF}$ & $\mathrm{CH}_{3} \mathrm{CONH}\left(\mathrm{CH}_{3}\right)_{2}-\mathrm{HCl}$ & $\mathrm{CH}_{3} \mathrm{CONH}\left(\mathrm{CH}_{3}\right)_{2}-\mathrm{H}_{2} \mathrm{SO}_{4}$ \\
\hline$\mu, \mathrm{D}$ & 4,35 & 4,90 & 6,08 & 6,38 \\
\hline $\mathrm{IP}, \mathrm{eV}$ & 9,42 & 9,82 & 9,95 & 9,68 \\
\hline $\mathrm{E}_{\text {номо }}$ & $-9,42$ & $-9,82$ & $-9,95$ & $-9,68$ \\
\hline $\mathrm{E}_{\text {LUMO }}$ & 0,93 & 0,57 & $-0,43$ & 0,51 \\
\hline$q\left(C_{1}\right)$, a unit of charging & 0,27 & 0,27 & 0,27 & $q\left(C_{5}\right) 0,28$ \\
\hline$q\left(C_{2}\right)$, a unit of charging & $-0,14$ & $-0,14$ & $-0,14$ & $q\left(C_{6}\right)-0,14$ \\
\hline$q\left(\mathrm{O}_{6}\right)$, a unit of charging & $-0,40$ & $-0,40$ & $-0,40$ & $\mathrm{q}\left(\mathrm{O}_{10}\right)-0,44$ \\
\hline $\mathrm{q}\left(\mathrm{N}_{7}\right)$, a unit of charging & $-0,05$ & $-0,05$ & $-0,48$ & $\mathrm{q}\left(\mathrm{N}_{11}\right)-0,04$ \\
\hline $\mathrm{q}\left(\mathrm{C}_{8}\right)$, a unit of charging & $-0,08$ & $-0,08$ & $-0,09$ & $q\left(C_{12}\right)-0,15$ \\
\hline $\mathrm{q}\left(\mathrm{C}_{12}\right)$, a unit of charging & $-0,09$ & $-0,09$ & $-0,09$ & $q\left(C_{16}\right)-0,09$ \\
\hline$q\left(\mathrm{H}_{16}\right)$, a unit of charging & - & 0,20 & 0,20 & $\mathrm{q}\left(\mathrm{H}_{20}\right) 0,31$ \\
\hline $\mathrm{q}\left(\mathrm{F}_{17}\right)$, a unit of charging & - & $-0,23$ & - & - \\
\hline $\mathrm{q}\left(\mathrm{Cl}_{17}\right)$, a unit of charging & - & - & $-0,24$ & - \\
\hline $\mathrm{q}\left(\mathrm{S}_{17}\right)$, a unit of charging & - & - & - & 2,49 \\
\hline $\mathrm{q}\left(\mathrm{O}_{2}\right)$, a unit of charging & - & - & - & $-0,82$ \\
\hline$q\left(\mathrm{O}_{37}\right)$, a unit of charging & - & - & - & $-0,92$ \\
\hline $\mathrm{q}\left(\mathrm{O}_{47}\right)$, a unit of charging & - & - & - & $-0,65$ \\
\hline
\end{tabular}

Table 3. The dipole moments, ionization potentials (IP), charge characteristics, the HOMO and LUMO energy ethylacetamide and its compounds with HF, $\mathrm{HCl}, \mathrm{H}_{2} \mathrm{SO}_{4}$.

\begin{tabular}{|c|c|c|c|c|}
\hline Electronic parameter & $\mathrm{CH}_{3} \mathrm{CONH}\left(\mathrm{C}_{2} \mathrm{H}_{5}\right)$ & $\mathrm{CH}_{3} \mathrm{CONH}\left(\mathrm{C}_{2} \mathrm{H}_{5}\right)-\mathrm{HF}$ & $\mathrm{CH}_{3} \mathrm{CONH}\left(\mathrm{C}_{2} \mathrm{H}_{5}\right)-\mathrm{HCl}$ & $\mathrm{CH}_{3} \mathrm{CONH}\left(\mathrm{C}_{2} \mathrm{H}_{5}\right)-\mathrm{H}_{2} \mathrm{SO}_{4}$ \\
\hline$\mu, \mathrm{D}$ & 3,52 & 4,82 & 8,43 & 4,32 \\
\hline $\mathrm{IP}, \mathrm{eV}$ & 9,68 & 10,11 & 9,79 & 9,89 \\
\hline $\mathrm{E}_{\text {номо }}$ & $-9,68$ & $-10,11$ & $-9,79$ & $-9,89$ \\
\hline $\mathrm{E}_{\text {LUMO }}$ & 1,00 & 0,56 & $-0,70$ & 0,59 \\
\hline$q\left(C_{1}\right)$, a unit of charging & $-0,13$ & $-0,14$ & $-0,11$ & $q\left(C_{4}\right)-0,13$ \\
\hline $\mathrm{q}\left(\mathrm{C}_{5}\right)$, a unit of charging & 0,24 & 0,26 & 0,20 & $\mathrm{q}\left(\mathrm{C}_{8}\right) 0,26$ \\
\hline$q\left(\mathrm{O}_{6}\right)$, a unit of charging & $-0,37$ & $-0,41$ & $-0,30$ & $\mathrm{q}\left(\mathrm{O}_{9}\right)-0,43$ \\
\hline $\mathrm{q}\left(\mathrm{N}_{7}\right)$, a unit of charging & $-0,06$ & $-0,04$ & $-0,02$ & $\mathrm{q}\left(\mathrm{N}_{10}\right)-0,04$ \\
\hline $\mathrm{q}\left(\mathrm{C}_{9}\right)$, a unit of charging & $-0,07$ & $-0,09$ & $-0,06$ & $\mathrm{q}\left(\mathrm{C}_{12}\right)-0,07$ \\
\hline $\mathrm{q}\left(\mathrm{C}_{10}\right)$, a unit of charging & $-0,12$ & $-0,14$ & $-0,13$ & $\mathrm{q}\left(\mathrm{C}_{13}\right)-0,12$ \\
\hline $\mathrm{q}\left(\mathrm{F}_{16}\right)$, a unit of charging & - & $-0,23$ & - & - \\
\hline $\mathrm{q}\left(\mathrm{H}_{17}\right)$, a unit of charging & - & 0,20 & - & - \\
\hline $\mathrm{q}\left(\mathrm{Cl}_{16}\right)$, a unit of charging & - & - & $-0,69$ & - \\
\hline $\mathrm{q}\left(\mathrm{H}_{17}\right)$, a unit of charging & - & - & 0,33 & - \\
\hline $\mathrm{q}\left(\mathrm{O}_{1}\right)$, a unit of charging & - & - & - & $-0,68$ \\
\hline $\mathrm{q}\left(\mathrm{S}_{2}\right)$, a unit of charging & - & - & - & 2,49 \\
\hline $\mathrm{q}\left(\mathrm{O}_{19}\right)$, a unit of charging & - & - & - & $-0,66$ \\
\hline $\mathrm{q}\left(\mathrm{O}_{21}\right)$, a unit of charging & - & - & - & $-0,87$ \\
\hline $\mathrm{q}\left(\mathrm{O}_{22}\right)$, a unit of charging & - & - & - & $-0,89$ \\
\hline
\end{tabular}




\section{Discussion of Results}

To establish peculiarities of the spatial structure by quantum-chemical method $\mathrm{PM}_{3}$ were calculated bond length as in the starting model of alkyl acetamide (methyl- dimethyl-, and ethylacetamide), and in their protonated with inorganic acids ( $\mathrm{HF}, \mathrm{HCl}, \mathrm{H}_{2} \mathrm{SO}_{4}$ ) forms. The "bond length" was chosen due to the fact that it allows you to make additional qualitative conclusions about the depth of the flowing interaction.

Comparison of the bond lengths in the model molecule methylacetamide and protonated forms of with inorganic acids shows the following:

- the process of protonation methylacetamide molecules mainly affects the interatomic distances in close proximity to the center of protonation;

- formed a new relationship is hydrogen, with the greatest depth-binding characteristic of the system methylacetamide-hydrochloric acid, i.e., it depends on the acid strength, taking part in the process of protonation methylacetamide.

Based on the analysis of the calculated bond lengths in the protonated forms of with inorganic acids dimethylacetamide can be noted the following:

- protonation with hydrochloric and sulfuric acids leads to changes in almost all of the bond lengths in a molecule of dimethylacetamide, while in the case of its protonation with hydrofluoric acid appreciable change in the geometry of the dimethylacetamide molecules is not observed;

- formed as a result of of protonation new bond in the case of participation hydrofluoric acid is covalent, and in the case of protonation with hydrochloric and sulfuric acid - hydrogen.

Basing on the results the analysis of features of the geometric structure of the protonated forms ethylacetamide (according to the values of bond lengths) can conclude the following:

- the process of protonation ethylacetamide taken to study with inorganic acids is accompanied by a change in the bond lengths between all the atoms in a molecule of the amide. In this case the largest changes are observed near the of protonation center;

- formed as a result of protonation new bond in almost all the new complexes is hydrogen in nature. The exception is a complex compound of dimethylacetamide with of hydrofluoric acid, in which the bond is covalent;

- depending the depth of interaction from the forces of inorganic acids is not observed.

The following electronic parameters for evaluation of the features of the electronic structure of quantum-chemical method PM3 were calculated: the dipole moment $(\mu)$, the first ionization potential (IP), the charge characteristics of the atoms of the skeleton molecules of amides and the atoms of the alkyl substituents (q), as well as the energy frontier orbitals ( $\mathrm{E}_{\mathrm{HOMO}}$ and $\left.\mathrm{E}_{\mathrm{LUMO}}\right)$.

\section{Conclusions}

So from an analysis of features of the spatial and electronic structures in systems ethylacetamide-inorganic acids it follows that the process of protonation N-substituted acetamide taken for study of inorganic acids leads to changes in almost all of the bond lengths in their molecules. At the same time the largest changes are observed near the protonation center. The length of the formed new bond in the case of methylacetamide and dimethylacetamide systems with inorganic acids depends on the acid strength. In the case of systems ethylacetamide-inorganic acid direct correlation the length of the connection of an inorganic acid strength is not observed. Process of protonation all examined N-alkylsubstituted acetamide fluoro-, hydrochloric and sulfuric acids leads to an increase asymmetry of electron redistribution in the molecule amide. Energetic costs spent on ionization studied objects in all cases are increasing at the transition from the initial to its protonated amide forms. Ourselves of protonation processes all studied amides are controlled by orbital processes.

It was found that protonation protonation of alkylsubstituted acetamide taken to study with inorganic acids is accompanied by increasing the asymmetry of the electronic redistribution. Energy costs for the ionization of studied alkylamides increased during the transition from the initial state to the protonated form.

\section{References}

[1] The chemistry of amides. Ed. Jabicky J. - London: Interscience, 1970. - $927 \mathrm{p}$.

[2] Nurakhmetov N. N. Amides // Results of science and technology. Series Physical Chemistry. - 1989. - T. 4. - P. 3-60.

[3] Gubanov V. A., Zhukov V. P., Litinskii S. A. Semi-empirical molecular orbital methods in quantum chemistry. - M.: Nauka, 1976. $-346 \mathrm{p}$.

[4] M. Dewar Theory of molecular orbitals in organic chemistry. M.: Mir, 1972. - 453 p.

[5] Zhidomirov G. M., Bagaturyants A. A., Abronin I. A. Applied quantum chemistry. - M.: Chemistry, 1979. - 325 p.

[6] T. Clark Computer chemistry. - M.: Mir, 1990. - 383 p.

[7] Solovyov M. E., Solovyev M. M. Computer chemistry. - M.: SOLON-Press, 2005. - 536 p.

[8] Ayginina T. V., Serazetdinov A. D., Yuldashev G. A. and others. The quantum-chemical calculation models (thio) amides of carboxylic acids and pyridinecarboxylic // Math. Academy of Sciences of the Republic of Kazakhstan. Chemical Series. - 1992. - № 4. - P. 59-63.

[9] Dey K., Selbin D. Theoretical Inorganic Chemistry. - M.: Chemistry, 1976. - 568 p. 
[10] Tautova E. N., Omarova R. A., Erkasov R. Sh. Comparative evaluation of the geometrical parameters of the benzamide compounds and salicylamide with perchloric acid // Proceedings of the international scientific-practical conf. "Valihanovsky read-12." - Kokshetau, 2007. - Volume 4. - P. 430-434.

[11] Omarova R. A., Tautova E. N., Erkasov R. Sh., Nurakhmetov N. N. Electronic features protonated molecule forms trichloroacetamide // Herald TREASURY. Chemical Series. 2004. - № 4 (36). - P. 314-316.

[12] Tautova E. N., Erkasov R. Sh., Omarova R. A. Evaluation of the electronic structure cyanogenacetamide compounds with inorganic acids composition of 2: 1 // Proceedings of the V International Scientific and Practical Conference. "Science and Education 2007". - Dnepropetrovsk, 2007. - Vol.10. - P. 811 .
[13] Tautova E. N., Omarova R. A., Erkasov R. Sh. Comparison of electronic and energy characteristics of the $\mathrm{O}-$ and $\mathrm{N}$ protonated forms of the molecule cyanogenacetamide // Proceedings of the International Scientific and Practical Conference. "Modern trends in theoretical and applied research." - Odessa, 2007. - T.18. - P. 3-7.

[14] Erkasov R. Sh., Tautova E. N., Omarova R. A. The structure of compounds derived from inorganic acids acetamide // Proceedings of the International Scientific and Practical Conference. "Valihanovsky read-12." - Kokshetau, 2007. Volume 4. - P. 328-332.

[15] Tautova E. N., Erkasov R. Sh., Omarova R. A. Assessment of geometrical structure ftoracetamide compounds trichloroacetamide, cyanogenacetamide with perchloric acid // Proceedings of the II International Scientific and Practical Conference. "Future development of science and technology "2006". - Dnepropetrovsk, 2006 - T.7. - P. 18-21. 